\title{
Options for Developing Salt-tolerant Crops
}

\author{
Wayne Loescher ${ }^{1}$, Zhulong Chan, and Rebecca Grumet \\ Graduate Program in Plant Breeding, Genetics, and Biotechnology, \\ Michigan State University, 328 PSSB, East Lansing, MI 48824-1325
}

Additional index words. salinization, compatible solute, sodium transport, osmoregulation, ion transport, compartmentation, osmoprotectant

\begin{abstract}
Soil salinization is an increasing problem worldwide and is often intensified by irrigation. Unfortunately, few new crop cultivars have been developed resistant to saline soils, a consequence, in part, of the complexity of plant responses to salt stress. There are now, however, several non-traditional options to improving salt tolerance as a result of recent progress in better understanding the mechanisms involved. These mechanisms include 1) exclusion of $\mathrm{Na}^{+}$and $\mathrm{Cl}^{-}$from plant tissues; 2) inclusion of these ions in inert compartments or tissues; and/or 3) some means of osmotic adjustment with solutes that are compatible with the metabolic machinery of the cell. Although there are very few horticultural examples, several lines of evidence indicate that reductions in salt sensitivity through exclusion or inclusion can be achieved by single gene modifications of the ion transport system. Similarly, single genes resulting in osmotic adjustment with solutes compatible with the metabolic machinery of the cell have resulted in significant increases in salt tolerance. Recent advances in sequencing, use of quantitative trait loci, and marker-assisted selection promise to provide other options for improving salt tolerance.
\end{abstract}

\section{BACKGROUND AND IMPORTANCE OF THE SALINITY PROBLEM}

Although estimates vary widely (Rozema and Flowers, 2008), soil salinization is a major factor reducing crop yields in the United States and globally. More than 800 million ha of land is salt-affected, which is over $6 \%$ of the world's land area (FAO Land and Plant Nutrition Management Service; Flowers and Yeo, 1995; Munns, 2009; Rengasamy, 2010). There are several causes. In dryland agriculture without irrigation in areas that receive rainfall less than 200 to $300 \mathrm{~mm} /$ year, capillarity allows salts in groundwater to reach the surface. This is particularly a problem in lessdeveloped countries with large and growing populations in arid climatic zones. Dryland (or non-irrigated) salinization is also common as a result of rising water tables over essentially saline sub-soils as a result of clearance of trees or other deep-rooted species, usually to make land available for rain-fed agriculture. This process has been well documented with land clearance in Australia (Rengasamy, 2006). Rising water tables also lead to waterlogging with oxygen deficiencies that reduce the ability of roots to exclude salts (BarrettLennard, 2003).

Salinity problems frequently result from irrigation. Indeed, it is an ancient problem that confronted the Sumerians (Epstein and Bloom, 2005). Estimates vary, with some indicating that that up to $50 \%$ of all irrigated lands may be salt-affected (Flowers, 1999; Szabolcs, 1989), and these numbers are expected to increase. Irrigation-induced (secondary) salinity effects are particularly problematic in arid

Received for publication 25 Mar. 2011. Accepted for publication 3 May 2011.

This paper was part of the colloquium "Improvement of Horticultural Crops for Abiotic Stress Tolerance" held 5 Aug. 2010 at the ASHS Conference, Palm Desert, CA, sponsored by the Vegetable Breeding (VGBR) Working Group, and co-sponsored by the Environmental Stress Physiology (STRS) Working Group.

${ }^{1}$ To whom reprint requests should be addressed; e-mail loescher@msu.edu. climatic zones. River systems in these regions with extensive irrigated agriculture supply the water for irrigation but also the salts dissolved in it. At $1 \mathrm{ppm}$ of salt, an acre foot of irrigation water contains over 1 ton of salt (1 meter ha contains over $8 \mathrm{MT}$ ), and Colorado river water in Southern California may be as high as 900 ppm (Anon, 1990). Under such conditions, salinization may be irreversible because fresh water limitations preclude leaching accumulated salts, particularly as urbanization and industrialization heighten competition for high-quality water (Evans, 1998; Rains and Goyal, 2003). Leaching is questionable because the leachate/saltwater created can cause further damage. Irrigation by drawing down rivers and aquifers in coastal areas may also lead to seawater incursions and tidal intrusions (Flowers, 1999).

Nonetheless, irrigation has been a major contributor to increases in global food production and to over $30 \%$ of total agricultural production (Munns and Tester, 2008). Thus, secondary salinization of irrigated lands is of major concern for global food production. In horticulture, although the scale of production is often smaller than that for the major agricultural crops, higher crop values justify irrigation investments, and intense cultivation in protected environments almost always requires irrigation with consequent salinity problems (Flowers, 1999). Elevated salt levels are also a problem with use of alternative water sources and reclaimed and nonpotable waters for irrigation in production and maintenance of landscape plants in arid environments (Niu and Cabrera, 2010). In short, wherever water is scarce and droughts are recurring, the many causes of soil salinity are major constraints to crop productivity (Bressanet al., 2008; Flowers and Yeo, 1995; Kronzucker and Britto, 2011; Läuchli and Lüttge, 2002; Munns, 1993).

Given the dimensions of the problem and the importance of sustainable irrigation to crop production, it is likely that salinization will become an even more significant issue in world agriculture during the 21 st century. Not surprisingly, a multitude of publications have addressed the many dimensions of the problem, including numerous reviews in the past few years (Apse and Blumwald, 2007; Ashraf et al., 2008; Bressan et al., 2008; Flowers and Colmer, 2008; Kronzucker and Britto, 2011; Mittler and Blumwald, 2010; Munns, 2009; Munns and Tester, 2008; Niu and Cabrera, 2010; Riadh et al., 2010; Tester and Langridge, 2010).

\section{IF SUCH A PROBLEM, WHY SO FEW NEW CROPS AND CULTIVARS RESISTANT TO SALINE SOILS?}

Why so little success? In the recent past, salinity was not seen as a major problem because salinized fields could be abandoned and replaced by others. Thus, there was little regional or global impact, even if there were major local effects. As a local problem, the conventional approach, e.g., drainage engineering, was the usual "solution" to facilitate leaching the salt below the root zone with high-quality water; however, this is often unfeasible in developing countries and where irrigation water is limited. Alternative approaches include more sophisticated irrigation techniques to minimize build-up of salt in the root zone, e.g., trickle and drip systems and use of amendments such as calcium sulfate to displace sodium adsorbed on the soil-cation exchange complex. However, these approaches often confront environmental, social, economic, and even legal challenges (Epstein and Bloom, 2005; National Research Council, 1989). The lack of success of breeding programs in developing commercially successful salt-tolerant crops is also often the result of breeders' preference for evaluating their genetic material under idealized conditions (Rengasamy, 2006).

\section{COMPLICATIONS: TWO COMPONENTS OF SALT STRESS}

There are two major components of salt stress (Munns, 2002). The first is osmotic, i.e. obtaining water from a soil of highly negative osmotic potential. Thus, there is an inseparable relationship between water and salt stress in which the first response to salt stress is 
dehydration/drought. This has implications for breeders, physiologists, and molecular biologists. What should they select for and at what stage of development: at stand establishment, at flowering, at fruit or seed set, at seed fill, or fruit growth? Short-term selection procedures would likely reflect a response to the osmotic strength of the external solution instead of a response to the toxic effect of the salt.

The second component is the result of specific ion effects. Although the focus is usually on dealing with high concentrations of potentially toxic sodium ions, carbonate and chloride ions are also problems (and all of these can result in other nutritional imbalances or deficiencies). Furthermore, these effects are often reduced when $\mathrm{Ca}^{++}$levels are high. Interactions between calcium levels and salt stress are common. Thus, a related complication is "sodicity," the presence of $\mathrm{Na}^{+}$relative to $\mathrm{Ca}^{++}$ and $\mathrm{Mg}^{++}$in the soil: expressed as the sodium adsorption ratio because most cations in the soil are attracted to the negative charges of clays. Salinity (sodicity) effects may, however, also involve different ion species, i.e., $\mathrm{Na}^{+}, \mathrm{Cl}^{-}$, $\mathrm{HCO}_{3}{ }^{-}, \mathrm{PO}_{4}{ }^{3-}, \mathrm{Ca}^{2+}, \mathrm{Mg}^{2+}, \mathrm{SO}_{4}{ }^{2-}$, and/or borate, and their interactions.

The situation is further complicated by the complexity of organismal responses to water deficit as Bohnert et al. (1995) and Bray $(1993,1997)$ have indicated. Responses begin with stress perception followed by one or more signal transduction pathways and the responses include changes at the cellular, physiological, and developmental levels. The responses also depend on severity and duration of the stress, genotype, developmental stage, and environmental factors. Furthermore, at the cellular level, water deficit may result from several stresses: drought, salt, and low or high temperature. This is confounded by terrestrial plants normally experiencing and responding to water stress almost daily. Separating normal and transient responses from abnormal longer-term drought effects is a challenge. As just one example of the complexity, in Arabidopsis in response to salt stress, numerous transcripts were up- or downregulated (1793 and 1446, respectively, with a fold difference greater than two, $P<$ 0.05) (Chan et al., 2011).

All this makes it difficult to uncover those responses that specifically enhance salt stress tolerance. However, the salt tolerance character is common. Marine algae inhabit an environment that is $\approx 0.5 \mathrm{M} \mathrm{NaCl}$, and coastal estuaries and salt marshes are often unusually productive (Bertness et al., 2004). An analysis (Flowers et al., 2010) of the evolution of salt tolerance in higher vascular plants indicated that salt tolerance (ability to tolerate at least $200 \mathrm{~mm} \mathrm{NaCl}$ ) has independently and repeatedly evolved many different times in angiosperms and in different ways. Nonetheless, there are some commonalities. Tolerance (to high salt levels in plant tissues) almost always requires the combination of several different traits: accumulation and compartmentation of ions for osmotic adjustment; the synthesis of compatible solutes; the ability to accumulate essential nutrients (especially
$\mathrm{K}^{+}$) in the presence of high concentrations of the ions generating salinity (particularly $\mathrm{Na}^{+}$); the ability to limit uptake and the entry of these saline ions into the transpiration stream and into the cytosol; and the ability to continue to regulate transpiration in the presence of high concentrations of $\mathrm{Na}^{+}$and $\mathrm{Cl}^{-}$(Flowers and Colmer, 2008). There is also the need to keep $\mathrm{Ca}^{++}$levels low in the cytosol and relatively high in the apoplast (Epstein and Bloom, 2005). Just as there is division of ions between the cytosol and the vacuole and apoplast, there may also be division of the whole plant into prioritized and non-prioritized tissues, e.g., between younger and older leaves, or mesophyll and epidermis, or fruits and meristems versus older leaves (Amtmann and Leigh, 2010).

\section{ANOTHER COMPLICATION-FEW CROP PLANTS DEMONSTRATE TRUE SALT TOLERANCE}

Although a few horticultural crops are moderate or true halophytes, e.g., tomato (Solanaceae), celery (Apiaceae), olive (Oleaceae), date palm (Arecaceae), asparagus (Liliaceae), and beet (Chenopodiaceae), most are sensitive, and some are very sensitive (glycophytes, nonhalophytes), e.g., pea, bean, chickpea, onion, citrus, and peach and related stone fruits. Unfortunately, although there are numerous comparisons of salt injury among ornamentals, only a little information is available on variation within species or their physiology when stressed (Kotuby-Amacher et al., 2000; Niu and Cabrera, 2010; Robins et al., 2009; Zhou et al., 2010). The term tolerance here may not be appropriate because glycophytes may use exclusion to some extent and avoidance mechanisms such as reabsorption of $\mathrm{Na}^{+}$ from the xylem stream and its recirculation down to the roots. For example, the ability of citrus to grow in somewhat saline soils is generally associated with exclusion or limited transport to the leaves by specific rootstocks rather than tolerance of ions in leaf tissues (Storey and Walker, 1998).

For a number of horticultural crops, natural variation exists within the species and their close relatives, e.g., strawberry (Hancock and Bringhurst, 1979), but with few exceptions, e.g., tomato (Foolad, 2004) and agronomic crops like rice, wheat, and barley (Islam et al., 2007; Nevo and Chen, 2010); this is largely unexplored. For reasons already mentioned, screening is difficult, particularly for yield, in which small, repeatable, and quantifiable differences are important. Introgressing salt tolerance into commercially important genotypes is invariably slow regardless of the species, but perennial woody crops present particular problems. As Munns (2009) has indicated, more targeted and feasible selection techniques are required. Furthermore, given the obvious complex polygenic nature of salt tolerance, knowledge of the target environment and understanding of the genetic basis for improvement will be necessary to develop appropriate screening methods.

Nonetheless, although salt tolerance is quite complex, and perhaps not amenable to simple approaches to breeding problems, both classical and non-traditional ("biotechnological") approaches are now common. Bressan et al. (2008) have outlined a list of strategies for enhancing salinity stress tolerance in crop species. These include traditional breeding with selection for yield, mutation breeding, screening within phenotype, and introducing germplasm from wild species into the crop species. There has been some progress with these approaches (Nevo and Chen, 2010; Omielan et al., 1991; Schachtman et al., 1989; Witcombe et al., 2008). A less traditional approach would entail generating new halophytic crops from halophytic wild species. Again, there are few, if any, horticultural examples. Nontraditional molecular approaches already underway include transgenic modifications and creation of genetic maps for quantitative trait locus (QTL) analyses and identification of candidate genes, and here there has been significant progress. Indeed, performance of transgenic plants under controlled conditions has sometimes been dramatic. Undergoing rapid development is transcript/protein/metabolite profiling of model and crop species and their stress-tolerant relatives so as to identify candidate genes and to develop better screening methods. Still in its infancy is the systems biology approach, which combines characters from mutation screening, genome sequencing, reverse and forward genetics, and computational tools into QTL-characterized backgrounds.

\section{MAJOR OPTIONS FOR CROP IMPROVEMENT}

Despite the complexities of salt tolerance, there are several major options for crop improvement. As already indicated, tolerance usually involves a combination of several mechanisms that appear to be nearly ubiquitous: 1) exclusion of $\mathrm{Na}^{+}$and $\mathrm{Cl}^{-}$; or 2) inclusion of these ions in inert compartments or tissues; and 3) exclusion/inclusion coupled with some means of osmotic adjustment with solutes that are compatible with the metabolic machinery of the cell. Accordingly, most of the examples of transgenic plants that demonstrate major improvements in tolerance involve transformation with single genes controlling one of these mechanisms. A comprehensive and frequently updated list of these is available at http://www.plantstress.com/.

Exclusion and inclusion are part of the ubiquitous and highly conserved ion homeostatic mechanisms present in all plants (glycophytes and halophytes). There is no sharp line between inclusion and exclusion/extrusion and some plants demonstrate a combination of both. With a two-phase growth response (first to drought and then to ion toxicity) (Munns, 2002), includers may experience reduced growth as a result of premature senescence of old leaves and thus reduced supply of assimilates. However, the result is to remove salt from the plant (more specifically, from the cytosol). Regardless of degree, salt tolerance of both halophytes and glycophytes is 
dependent on the homeostatic mechanisms that control net ion uptake across the plasma membrane and compartmentation into the vacuole. Furthermore, cells of virtually all plants possess the capability to sense and respond to a saline environment (Amtmann and Leigh, 2010). Ion concentrations and transport are tightly controlled and thus the question is to what extent do halophytes have unique capabilities that distinguish them from glycophytes. Salt-sensitive plants generally may tolerate moderate salinity because of root mechanisms that reduce movement of harmful ions to the shoot. Halophytes generally have a greater capacity to tolerate vacuolar compartmentalization of ions in leaf cells (Flowers et al., 2010).

\section{MANIPULATING ION HOMEOSTASIS - TWO APPROACHES}

Manipulating ion homeostasis would appear formidably complex. In Arabidopsis, for example, transport proteins represent at least $5 \%$ of the genome (Maser et al., 2001), and there are $35 \mathrm{~K}^{+}$transporters. Conductance and selectivity of many of these transporters are also known to be regulated by various factors: substrates and levels of other ions (particularly $\mathrm{Ca}^{++}$), membrane electrical potential (some are depolarization- or hyperpolarization-activated and others are voltage-insensitive), and response to ligands and stimuli (gated by cyclic nucleotides or amino acids or activated by reactive oxygen species) (Kronzucker and Britto, 2011). However, several lines of evidence now indicate that tolerance can be achieved by single gene modifications of the ion transport system. After research showing that expression of an Arabidopsis vacuolar $\mathrm{H}^{+}$pyrophosphatase could improve salt tolerance when expressed in yeast (Gaxiola et al., 1999), this gene was then overexpressed in Arabidopsis (Gaxiola et al., 2001) and more recently in cotton (Pasapula et al., 2011) and bentgrass (Li et al., 2010b) and plants were much more resistant to high concentrations of $\mathrm{NaCl}$ and drought than their wild types. Transgenic plants accumulated more $\mathrm{Na}^{+}$and $\mathrm{K}^{+}$in their leaf tissues than the wild type. Moreover, direct measurements on vacuolar membrane vesicles derived from the $A V P 1$ transgenic plants and from wild type demonstrated that vesicles from transgenic plants had enhanced cation uptake.

Similarly, Blumwald and collaborators (Apse et al., 2003; Zhang and Blumwald, 2001) showed that overexpression in tomato of a specific vacuolar $\mathrm{Na}^{+} / \mathrm{H}^{+}$antiporter, AtNHX1, could dramatically improve vegetative growth and fruit yield. Comparable results have since been obtained in a number of crops, e.g., Brassica (Zhang et al., 2001), rice (Ohta et al., 2002), maize (Yin et al., 2004), wheat (Xue et al., 2004), cotton (He et al., 2005), tobacco ( $\mathrm{Lu}$ et al., 2005), and sugar beet (Liu et al., 2008). For a perspective on this antiporter's potential in plant breeding, see Hanana et al. (2009). However, other attempts to express similar $\mathrm{Na}^{+} / \mathrm{H}^{+}$antiporters have not been so successful, thus questioning a broad role for vacuolar NHX1-like proteins as effective $\mathrm{Na}^{+}$scavengers in planta (Leidi et al., 2010). On the other hand, in Arabidopsis, a similar transporter, AtHKT1;1, drives elevated leaf $\mathrm{Na}^{+}$. This has been previously linked to elevated salinity tolerance, and geographical distribution indicates its enrichment in populations associated with saline and coastal soils, thus providing genetic evidence supporting a role for AtHKT1;1 in local adaptation to potentially saline-impacted environments (Baxter et al., 2010).

In a related approach, AtHKT1;1 improved sodium $\left(\mathrm{Na}^{+}\right)$exclusion and salinity tolerance when expressed in Arabidopsis root cortical and epidermal cells (Moller et al., 2009) and in rice when expressed and targeted to the mature root stele (Plett et al., 2010). Constitutive 35Spromoted expression did not have that effect. Interestingly, in the transgenic Arabidopsis plants overexpressing AtHKT1; 1 in the cortex and epidermis, the native AtHKT1;1 gene responsible for $\mathrm{Na}^{+}$retrieval from the transpiration stream was also upregulated as was expression of the vacuolar pyrophosphatases (in both Arabidopsis and rice) necessary to move the additional stored $\mathrm{Na}^{+}$into the vacuoles of these cells.

In another approach, Zhu and colleagues (Qiu et al., 2002; Wu et al., 1996; Zhu, 2002) focused on the SOS signal transduction pathway in which the key ion transport step is SOS- 1 , a plasma membrane $\mathrm{Na}^{+} / \mathrm{H}^{+}$antiporter that appears to control long-distance sodium transport in plants (Shi et al., 2002). Although SOS-1 is only a part of a complex signaling pathway that controls sodium uptake by the root system (Bressan et al., 2008; Yang et al., 2009), overexpression of SOS-1 improved salt tolerance in Arabidopsis (Shi et al., 2003). It is also interesting that the AtSOS1 transcript is upregulated under salt stress, and the stability of the transcript itself is maintained in the presence of $\mathrm{NaCl}$ (Shi et al., 2000; Ward et al., 2003). The SOS-1 protein, however, appears to play other roles in addition to $\mathrm{Na}^{+}$transport (Kronzucker and Britto, 2011; Oh et al., 2010), which may confound interpretation of the ectopic expression results.

\section{A THIRD APPROACH: OSMOTIC ADJUSTMENT WITH COMPATIBLE SOLUTES}

Osmotic adjustment or osmoregulation can be achieved by several means, e.g., through succulence (of leaves), salt and solute accumulation, or shedding of older leaves, or a combination of these factors. More frequently, however, adjustment involves compatible solutes, classes of compounds that can accumulate in the cytosol without damaging enzymes. See Loescher and Everard (2000) and Rhodes et al. (2002) for discussions. For example, activities of enzymes extracted from several mangrove algae were inhibited with increasing $\mathrm{NaCl}$ up to $600 \mathrm{~mm}$. In contrast, when combined with equimolar concentrations of a mixture of several compatible solutes, mannitol, sorbitol, and a heteroside (a dimer of a hexose and glycerol), enzyme function was not inhibited (Karsten et al., 1996). Compatible solutes are thought to function by means of preferential exclusion, somehow stabilizing and ordering water molecules in the hydration shell surrounding macromolecules. Ions are prevented from penetrating the shell so that protein and solute do not come into direct contact (Timasheff, 1993). Compatible solutes represent a comparatively easy approach evolutionarily because tolerance only requires synthesis of one compound (through one biosynthetic pathway or modification of an existing pathway).

This approach is by no means uncommon. All organisms tolerate abiotic stress to some degree by accumulating "compatible" solutes (Rhodes et al., 2002). Thus, introduction of gene(s) for compatible solute biosynthesis with accumulation in the right compartment(s) could enhance dehydration and salt stress tolerance. There are a numerous candidates (Table 1) and now many lines of evidence supporting a beneficial effect of increased compatible solute production. Some of these solutes are primary photosynthetic products. Sucrose, for example, is present in all higher plants, sorbitol is ubiquitous in Rosaceous pome and stone fruits, and mannitol is found in 70 higher plant families (Loescher and Everard, 2000). Salinity often affects synthesis and accumulation of many of these compounds. For example, root-zone salinity altered raffinose oligosaccaride metabolism and transport in Coleus (Gilbert et al., 1997). In salt-stressed celery, mannitol becomes the predominant photosynthetic product (Everard et al., 1994). Sorbitol accumulates to high levels in the halophyte, Plantago maritime, up to 300 $\mathrm{mmol} \cdot \mathrm{g}^{-1}$ dry wt in shoots and $225 \mathrm{mmol}$ in roots) under saline $(400 \mathrm{~mm} \mathrm{NaCl})$ conditions (Ahmad et al., 1979). In the facultative halophyte ice plant (Mesembryanthemum crystallinum), a novel methyl transferase (Imt1) is induced by osmotic stress leading to the synthesis of ononitol from inositol

Table 1. Compatible solutes (osmoprotectants) found in higher plants. ${ }^{\mathrm{z}}$

\begin{tabular}{ll}
\hline Candidates (classes of compatible solutes) & \multicolumn{1}{c}{ Examples } \\
\hline Quaternary ammonium zwitterions & Glycine betaine \\
Amino acids & Particularly praline \\
Cyclic polyols & Inositol and its methylated derivatives ononitol, \\
& pinitol, quebrachitol \\
Non-reducing sugars & Sucrose, raffinose, stachyose, verbascose, trehalose \\
Acyclic polyols (sugar alcohols) & Sorbitol (glucitol), mannitol, adonitol, ribitol, \\
& perseitol, and galactitol \\
\hline zThe amino and ammonium
\end{tabular}

${ }^{\mathrm{z}}$ The amino and ammonium compounds have no net charge at physiological $\mathrm{pH}$ and the cyclic and acyclic polyols and sugars are all non-reducing carbohydrates. 
(Vernon and Bohnert, 1992). When a gene encoding Imt1 was introduced into tobacco, transformants appeared phenotypically normal, exhibited Imt1 enzyme activity, accumulated ononitol, and were salt-tolerant (Sheveleva et al., 1997). In transgenic tobacco engineered by introduction of a bacterial gene for mannitol 1-phosphate dehydrogenase, transgenic plants with mannitol had an increased ability to tolerate high salinity (Tarczynski et al. (1993), and later work (Shen et al., 1997) showed that there was increased resistance to oxidative stress when mannitol biosynthesis was specifically targeted to chloroplasts. In petunia, this gene improved chilling tolerance (Chiang et al., 2005). Zhifang and Loescher (2003) showed that Arabidopsis plants transgenic for the celery mannose 6-phosphate reductase (M6PR) were quite salt-tolerant, phenotypically normal, accumulated mannitol to levels nearly as high as sucrose, and at onset of flowering accumulated high levels of a mannitol-glucose dimer. Later work showed that these plants were also photosynthetically normal and able to maintain high rates even at substantial levels of salt stress (Sickler et al., 2007). More recently, direct competition experiments between each transgenic line and corresponding parental genotypes in field tests have shown that M6PR plants have equivalent or greater fitness than their wild-type parents (Bigelow et al., 2010).

Amino compounds, e.g., glycine betaine and proline, have long been known to be involved in some forms of abiotic stress tolerance (Ashraf and Foolad, 2007; Rhodes and Hanson, 1993), and there is clear evidence for their roles in salt tolerance. Plants transformed with various genes for metabolism of these compounds are often more tolerant, to salt, drought, or both, either by increasing biosynthesis (Hayashi et al., 1997; Holmstrom et al., 2000; Hong et al., 2000; Kishor et al., 1995; Nomura et al., 1995) or by decreasing degradation (Nanjo et al., 1999). Horticultural examples include petunia in which there was improved drought tolerance (Yamada et al., 2005) and potato with improved salt tolerance (Hmida-Sayari et al., 2005).

Whatever the gene or the compatible solute, compartmentation is critical. It is not likely that compatible solutes are uniformly distributed throughout the cell. This distribution question is rarely answered, but it is essential to the proposed function because there may be an insufficient quantity of the compatible solute to achieve the desired effect if not limited to the cytoplasm or specific organelles such as chloroplasts. As already shown, targeting mannitol biosynthesis to the chloroplast effectively increased resistance to oxidative stress (Shen et al., 1997). Keller and Matile (1989) showed that in celery, petiole parenchyma mannitol was predominantly stored in the vacuole $(81 \%)$ with a lesser amount in the cytosol (19\%), but cytosolic concentrations were calculated to reach 300 $\mathrm{mm}$, adequate to balance high levels of salts in apoplast and vacuole because the cytosol represents a very small fraction of total cellular volume.

\section{COMPATIBLE SOLUTES VERSUS OSMOPROTECTANTS}

Compatible solutes are assumed to accumulate to high concentrations without interfering with normal metabolism, but protective effects are often seen at levels too low for significant osmotic effects. Thus, "osmoprotectant" functions also have been suggested, e.g., scavenging of free radicals (acting to quench effects of reactive oxygen species), stabilization of macromolecular and membrane structures, or activity as low-molecular-weight chaperones (Bohnert and Jensen, 1996). Recent studies, however, suggest other osmoprotectant mechanisms. A transcriptome analysis of the presence of the M6PR transgene in salt stress-tolerant Arabidopsis (Chan et al., 2011) showed that in addition to mannitol biosynthesis, there was also activation of the downstream ABA pathway by upregulation of ABA receptor genes (PYL4, PYL5, and PYL6) and downregulation of $P P 2 C$ genes ( $A B I 1$ and $A B I 2)$. In M6PR transgenic lines, there were also increases in transcripts related to redox levels and cell wall strengthening pathways. These data indicate that mannitol-enhanced stress tolerance is attributable at least in part to increased expression of a variety of stress inducible genes. Similarly, Chen and Murata (2011) have shown that low levels of glycine betaine, applied exogenously or generated by transgenes for glycine betaine biosynthesis, can induce the expression of certain stressresponsive genes, including those for enzymes that scavenge reactive oxygen species. Kathuria et al. (2009) showed that glycine betaine-induced water stress tolerance in rice is associated with upregulation of a number of stress-responsive genes. Overall, 165 genes were upregulated more than twofold, and of these, at least 50 genes are known to be involved in plant stress responses. Somewhat similar results were also seen with overexpression of the trehalose-6-phosphate phosphatase gene in rice (Ge et al., 2008). Whether such effects are common in plants transgenic for osmoprotectants remains to be determined. However, introducing a metabolite or metabolic pathways in a species in which such are normally absent might be expected to affect flux through other pathways (Eastmond and Graham, 2003).

Similarly, perturbing ion homeostasis should be expected to affect regulation and/ or flux through other transporters and pathways linked to these systems. For example, insertional mutagenesis of the AtNHX1 vacuolar antiporter (Sottosanto et al., 2004) resulted in changes in expression of genes involved in intracellular vesicular trafficking, protein targeting, and other cellular processes. When AtHKT1;1 was expressed specifically in the root cortical and epidermal cells of Arabidopsis, the native AtHKT1;1 gene responsible for $\mathrm{Na}^{+}$retrieval from the transpiration stream was also upregulated, and there was also a significant increase in expression of vacuolar pyrophosphatases (Plett et al., 2010).

\section{OTHER FACTORS-REGULATORY DETERMINANTS, TRANSCRIPTION FACTORS, AND SIGNAL PATHWAY INTERMEDIATES}

Although modulating osmolyte metabolism and transport proteins might not have been expected to result in significant changes in gene expression, a number of transgenes used for stress tolerance are transcription factors that up- or downregulate gene expression. Unfortunately, the molecular sensing, signaling, and response pathways that govern biotic and abiotic stress tolerance are not yet well understood in many plant species, although functional analyses in Arabidopsis of many genes for transcription factors have revealed a complex and overlapping hierarchy of signaling networks between many different stresses (Bressan et al., 2008; Shinozaki et al., 2003; Witcombe et al., 2008). Much of this work has been carried out in Arabidopsis with the SOS signal pathway associated with salt tolerance (Bressan et al., 2008) or the dehydration-responsive element binding (DREB)/CBF (C-repeat binding factors) transcriptional activation factors (Gilmour et al., 2004; Shinozaki et al., 2003). There are now numerous examples of stress-tolerant plants transgenic for DREB/CBF with either constitutive promoters (often resulting in dwarfing) or under control of an Arabidopsis stress-inducible promoter (to reduce negative effects) (e.g., Achard et al., 2008; Gilmour et al., 2004; Haake et al., 2002; Jaglo-Ottosen et al., 1998; Liu et al., 1998; Pino et al., 2007).

Regulatory intermediates that modulate plant salt stress responses include SOS3 (Ca21-binding protein), SOS2 kinase, Ca21dependent protein kinases, and mitogen-activated protein kinases (Bressan et al., 2008). Other signal intermediates have been implicated in the response to salt, many through ectopic expression in transgenic plants. For example, the basic Leu zipper motif, MYB and MYC, AP2 family, PHD type, and zinc finger transcription factors, including rd22BP1 (MYC), AtMYB2 (MYB), and ALFIN1 (zinc finger), all interact with promoters of osmotic-regulated genes (Abe et al., 2003; Bhatnagar-Mathur et al., 2008; Gao et al., 2007; Kant et al., 2008; Oh et al., 2009; Shin et al., 2011; Winicov, 2000; Yang et al., 2011; Zhang et al., 2011; Zhu, 2002). Other examples include constitutive expression of CBF/DREB transcription factors in Arabidopsis, which leads increased expression of the CBF/DREB regulon genes, including LEA, dehydrin, antifreeze, and galactinol synthesis-related genes as well as factors involved in signal transduction and gene regulation (Fowler and Thomashow, 2002; James et al., 2008; Maruyama et al., 2004; Pino et al., 2007; Seki et al., 2001; Vogel et al., 2005; Zhang et al., 2004).

\section{OTHER OPTIONS-PLANT HORMONES AND STRESS SENSORS}

It is also now clear that the hormone ABA accumulates in plant tissues in response to 
biotic, abiotic, and especially osmotic-based stresses, including salt stress (Harb et al., 2010; Himmelbach et al., 2003; Zhu, 2002). $\mathrm{ABA}$ is also a major component of plant stress response signaling networks (the $A R E B / A B F$ and $M y c / M y b$ regulons that are involved in abiotic stress responses), and the ABA receptor family appears to be highly conserved in crop species, which suggests opportunities for manipulating stress tolerance in crops (Klingler et al., 2010). Consequently, there are now a number of approaches to stress tolerance that modulate ABA sensitivities ( $\mathrm{Li}$ et al., 2010a; Ren et al., 2010; Saavedra et al., 2010; Santiago et al., 2009; Yang et al., 2010), regulation (Park et al., 2009), or biosynthesis (Ko et al., 2006), and the results have demonstrated improved salt and/or drought tolerance when expressed in transgenic plants.

Another hormone option is cytokinin biosynthesis. Upregulation or overexpression of $P-S A R K: \because I P T$, a key step in cytokinin metabolism, results in delayed leaf senescence with a significant improvement in drought tolerance (Rivero et al., 2007). The mechanism relates to drought often stimulating senescence and abscission and with a cytokininmediated delay in senescence photosynthetic capacity is maintained (Rivero et al., 2010). Although there is as yet no evidence that this specific mechanism translates into salinity tolerance, there is clear evidence that cytokinins are involved in the salinity response (de la Pena et al., 2008; Mason et al., 2010; Tran et al., 2007).

Another approach may be identification of stress sensors (as the primary step in a plant's response). Putative sensors have been identified (Mikolajczyk et al., 2000; Urao et al., 1999), and there are numerous possibilities, e.g., physical changes in membrane proteins and kinases (Seo et al., 2010), release of metabolites like ATP (Baena-González and Sheen, 2008), or accumulation of reactive oxygen species activating various metabolic or signaling pathways (Miller et al., 2009). However, their specific functions remain elusive and analyses are complicated by the numbers and interactions of potential candidates and the possibility that there may be substantial redundancies (Mittler and Blumwald, 2010).

\section{OTHER ISSUES-THE HORTICULTURAL PERSPECTIVE}

Despite the evidence, particularly in model species, for non-traditional (transgenic) alternatives to classical plant breeding to achieve salinity tolerance, there are few examples of horticultural crops transformed to be salt-tolerant, even fewer are in field testing, and none are in production. Indeed, there is little evidence that breeding for salt tolerance is a priority for any horticultural crop. This may reflect higher returns that justify investments in more sophisticated irrigation and drainage systems that avoid salt stresses, or it may also represent the limited resources available for improvement of the so-called minor crops. There are also other problems. Although there has been substantial progress in plant regeneration and transformation, creating transgenic plants is not yet routine for many crop plants (Barampuram and Zhang, 2011), and growers may also be reluctant to adopt transgenic crops that may encounter consumer acceptance and regulatory problems. Nonetheless, salinity remains a major threat to the sustainable irrigation required to meet the food demands of increasing populations and economic development (Flowers, 2004). Consequently, although progress might be slow, and as Munns (2009) has indicated, with the natural diversity that exists, and the current consumer acceptance issues, consideration could be given to using the substantial progress made in genes identified as markers for naturally occurring diversity or linked molecular markers to physiological traits. Indeed, there may be a relatively small number of QTL governing the complex physiological processes involved in the combination of drought stress and ion toxicities that comprise salinity tolerance. Uses of molecular (microsatellite) markers and QTL mapping are progressing rapidly, the techniques are relatively inexpensive, and they do not require extensive phenotypic screening (with the problems inherent in establishing reproducible levels of drought and salt stress). Given the extraordinary progress in sequencing (http://www.ncbi.nlm.nih.gov/ genomes/leuks.cgi), apparent similarities between species in signaling (Mochida et al., 2010), and the syntenic relationships between species, these can increasingly be exploited for comparative genomics analyses (Bennetzen, 2002) and dramatically improve the efficiencies in genetic mapping and ultimately crop improvement.

\section{Literature Cited}

Abe, H., T. Urao, T. Ito, M. Seki, K. Shinozaki, and K. Yamaguchi-Shinozaki. 2003. Arabidopsis AtMYC2 (bHLH) and AtMYB2 (MYB) function as transcriptional activators in abscisic acid signaling. Plant Cell 15:63-78.

Achard, P., F. Gong, S. Cheminant, M. Alioua, P. Hedden, and P. Genschik. 2008. The coldinducible CBF1 factor-dependent signaling pathway modulates the accumulation of the growth-repressing DELLA proteins via its effect on gibberellin metabolism. Plant Cell 20:2117-2129.

Ahmad, I., F. Larher, and G.R. Stewart. 1979. Sorbitol, a compatible osmotic solute in Plantago maritima. New Phytol. 82:671-678.

Amtmann, A. and R. Leigh. 2010. Ion homeostasis, p. 245-262. In: Pareek, A., S.K. Sopory, H.J. Bohnert, and Govindjee (eds.). Abiotic stress adaptation in plants: Physiological, molecular and genomic foundation. Springer, Dordrecht, The Netherlands.

Anon, 1990. Western fertilizer handbook, horticulture edition. In: Ludwick A.E., et al. (eds.). Calif. Fertilizer Assoc, Interstate Pubs., Danville, IL.

Apse, M.P. and E. Blumwald. 2007. Na+ transport in plants. FEBS Letters 581:2247-2254.

Apse, M.P., J.B. Sottosanto, and E. Blumwald. 2003. Vacuolar cation $/ \mathrm{H}^{+}$exchange, ion homeostasis, and leaf development are altered in a T-DNA insertional mutant of AtNHX1, the Arabidopsis vacuolar $\mathrm{Na}^{+} / \mathrm{H}^{+}$antiporter. Plant J. 36:229-239.

Ashraf, M., H.R. Athar, P.J.C. Harris, and T.R. Kwon. 2008. Some prospective strategies for improving crop salt tolerance. Adv. Agron. 97:45-110.
Ashraf, M. and M.R. Foolad. 2007. Roles of glycine betaine and proline in improving plant abiotic stress resistance. Environ. Exp. Bot. 59:206-216.

Baena-González, E. and J. Sheen. 2008. Convergent energy and stress signaling. Trends Plant Sci. 13:474-482.

Barampuram, S. and Z.J. Zhang. 2011. Recent advances in plant transformation, p. 1-35. In: Birchler, J.A. (ed.). Plant chromosome engineering: Methods and protocols, methods in molecular biology. Springer, Dordrecht, The Netherlands.

Barrett-Lennard, E.G. 2003. The interaction between waterlogging and salinity in higher plants: Causes, consequences and implications. Plant Soil 253:35-54.

Baxter, I., J.N. Brazelton, D.N. Yu, Y.S. Huang, B. Lahner, E. Yakubova, Y. Li, J. Bergelson, J.O. Borevitz, M. Nordborg, O. Vitek, and D.E. Salt. 2010. A coastal cline in sodium accumulation in Arabidopsis thaliana is driven by natural variation of the sodium transporter AtHKT 1;1. PLoS Genet. 6:11.

Bennetzen, J. 2002. The rice genome-Opening the door to comparative plant biology. Science 296:60.

Bertness, M., B.R. Silliman, and R.L. Jefferies. 2004 Salt marshes under siege. Amer. Sci. 92:54-61.

Bhatnagar-Mathur, P., V. Vadez, and K. Sharma. 2008. Transgenic approaches for abiotic stress tolerance in plants: Retrospect and prospects. Plant Cell Rpts. 27:411-424.

Bigelow, P., W. Loescher, and R. Grumet. 2010. The competitive fitness of abiotic stress tolerance enhancing transgenes under field conditions. Amer. Soc. Plant Biol. Ann. Mtg. P-07106.

Bohnert, H.J. and R.G. Jensen. 1996. Strategies for engineering water-stress tolerance in plants. Trends Biotechnol. 14:89-97.

Bohnert, H.J., D.E. Nelson, and R.G. Jensen. 1995. Adaptations to environmental stresses. Plant Cell 7:1099-1111.

Bray, E.A. 1993. Molecular responses to water deficit. Plant Physiol. 103:1035-1040.

Bray, E.A. 1997. Plant responses to water deficit. Trends Plant Sci. 2:48-54.

Bressan, R.A., H.J. Bohnert, and P.M. Hasegawa. 2008. Genetic engineering for salinity stress tolerance. Adv. Plant Biochem.Mol. Biol. 1: 347-384.

Chan, Z., R. Grumet, and W. Loescher. 2011. Global gene expression analysis of transgenic, mannitol-producing and salt tolerant Arabidopsis thaliana indicates widespread changes in expression of abiotic- and biotic-stress related genes. J. Expt. Bot. (in press).

Chen, T.H.H. and N. Murata. 2011. Glycinebetaine protects plants against abiotic stress: Mechanisms and biotechnological applications. Plant Cell Environ. 34:1-20.

Chiang, Y.J., C. Stushnoff, and A.E. McSay. 2005 Overexpression of mannitol-1-phosphate dehydrogenase increases mannitol accumulation and adds protection against chilling injury in petunia. J. Amer. Soc. Hort. Sci. 130:605-610.

de la Pena, T.C., C.B. Carcamo, L. Almonacid, A. Zaballos, M.M. Lucas, D. Balomenos, and J.J. Pueyo. 2008. A salt stress-responsive cytokinin receptor homologue isolated from Medicago sativa nodules. Planta 227:769-779.

Eastmond, P.J. and I.A. Graham. 2003. Trehalose metabolism: A regulatory role for trehalose-6phosphate? Curr. Opin. Plant Biol. 6:231-235.

Epstein, E. and A.J. Bloom. 2005. Mineral nutrition of plants: Principles and perspectives. 2nd Ed. Sinauer Associates, Inc., Sunderland, MA.

Evans, L.T. 2003. Agricultural intensification and sustainability. Outlook on Agriculture 32:83-89. 
Everard, J.D., R. Gucci, S.C. Kann, J.A. Flore, and W.H. Loescher. 1994. Gas exchange and carbon partitioning in the leaves of celery (Apium graveolens L.) at various levels of root zone salinity. Plant Physiol. 106:281-292.

FAO Land and Plant Nutrition Management Service. <http://www.fao.org/ag/agl/agll/spush>.

Flowers, T.J. 1999. Salinisation and horticultural production. Sci. Hort. 78:1-4.

Flowers, T.J. 2004. Improving crop salt tolerance. J. Expt. Bot. 55:639-648.

Flowers, T.J. and T.D. Colmer. 2008. Salinity tolerance in halophytes. New Phytol. 179:945-963.

Flowers, T.J., H.K. Galal, and L. Bromham. 2010. Evolution of halophytes: Multiple origins of salt tolerance in land plants. Funct. Plant Biol. 37:604-612.

Flowers, T.J. and A.R. Yeo. 1995. Breeding for salinity resistance in crop plants: Where next? Funct. Plant Biol. 22:875-884.

Foolad, M.R. 2004. Recent advances in genetics of salt tolerance in tomato. Plant Cell Tissue Organ Cult. 76:101-119.

Fowler, S. and M.F. Thomashow. 2002. Arabidopsis transcriptome profiling indicates that multiple regulatory pathways are activated during cold acclimation in addition to the CBF cold response pathway. Plant Cell 14:1675-1690.

Gao, J.-P., D.-Y. Chao, and H.-X. Lin. 2007. Understanding abiotic stress tolerance mechanisms: Recent studies on stress response in rice. J. Integr. Plant Biol. 49:742-750.

Gaxiola, R.A., J.S. Li, S. Undurraga, L.M. Dang, G.J. Allen, S.L. Alper, and G.R. Fink. 2001. Drought- and salt-tolerant plants result from overexpression of the AVP1 $\mathrm{H}^{+}$-pump. Proc. Natl. Acad. Sci. USA 98:11444-11449.

Gaxiola, R.A., R. Rao, A. Sherman, P. Grisafi, S.L. Alper, and G.R. Fink. 1999. The Arabidopsis thaliana proton transporters, AtNhx1 and Avp1, can function in cation detoxification in yeast. Proc. Natl. Acad. Sci. USA 96:1480-1485.

Ge, L.F., D.Y. Chao, M. Shi, M.Z. Zhu, J.P. Gao, and H.X. Lin. 2008. Overexpression of the trehalose-6-phosphate phosphatase gene OsTPP1 confers stress tolerance in rice and results in the activation of stress responsive genes. Planta 228:191-201.

Gilbert, G.A., C. Wilson, and M.A. Madore. 1997. Root-zone salinity alters raffinose oligosaccaride metabolism and transport in Coleus. Plant Physiol. 115:1267-1276.

Gilmour, S.J., S.G. Fowler, and M.F. Thomashow. 2004. Arabidopsis transcriptional activators $\mathrm{CBF} 1, \mathrm{CBF} 2$, and $\mathrm{CBF} 3$ have matching functional activities. Plant Mol. Biol. 54:767-781.

Haake, V., D. Cook, J.L. Riechmann, O. Pineda, M.F. Thomashow, and J.Z. Zhang. 2002. Transcription factor CBF4 is a regulator of drought adaptation in Arabidopsis. Plant Physiol. 130:639-648.

Hanana, M., O. Cagnac, M. Zarrouk, and E. Blumwald. 2009. Biological Roles of NHX vacuolar antiport: Achievements and prospects of plant breeding. Botany-Botanique 87:1023-1035.

Hancock, J.F. and R.S. Bringhurst. 1979. Ecological differentiation in perennial, octoploid species of Fragaria. Amer. J. Bot. 66:367-375.

Harb, A., A. Krishnan, M.M.R. Ambavaram, and A. Pereira. 2010. Molecular and physiological analysis of drought stress in Arabidopsis reveals early responses leading to acclimation in plant growth. Plant Physiol. 154:1254-1271.

Hayashi, H., Alia, L. Mustardy, P. Deshnium, M. Ida, and N. Murata. 1997. Transformation of Arabidopsis thaliana with the coda gene for choline oxidase; accumulation of glycine-betaine and enhanced tolerance to salt and cold stress. Plant J. 12:133-142.
He, C., J. Yan, G. Shen, L. Fu, A.S. Holaday, D. Auld, E. Blumwald, and H. Zhang. 2005. Expression of an Arabidopsis vacuolar sodium/ proton antiporter gene in cotton improves photosynthetic performance under salt conditions and increases fiber yield in the field. Plant Cell Physiol. 46:1848-1854.

Himmelbach, A., Y. Yang, and E. Grill. 2003. Relay and control of abscisic acid signaling. Curr. Opin. Plant Biol. 6:470-479.

Hmida-Sayari, A., R. Gargouri-Bouzid, A. Bidani, L. Jaoua, A. Savoure, and S. Jaoua. 2005. Overexpression of delta(1)-pyrroline-5-carboxylate synthetase increases proline production and confers salt tolerance in transgenic potato plants. Plant Sci. 169:746-752.

Holmstrom, K.O., S. Somersalo, A. Mandal, T.E. Palva, and B. Welin. 2000. Improved tolerance to salinity and low temperature in transgenic tobacco producing glycine betaine. J. Expt. Bot. 51:177-185.

Hong, Z., K. Lakkineni, Z. Zhang, and D.P. Verma. 2000. Removal of feedback inhibition of delta(1)pyrroline-5-carboxylate synthetase results in increased proline accumulation and protection of plants from osmotic stress. Plant Physiol. 122: $1129-1136$.

Islam, S., A.I. Malik, A.K.M.R. Islam, and T.D. Colmer. 2007. Salt tolerance in a Hordeum marinum-Triticum aestivum amphiploid, and its parents. J. Expt. Bot. 58:1219-1229.

Jaglo-Ottosen, K.R., S.J. Gilmour, D.G. Zarka, O. Schabenberger, and M.F. Thomashow. 1998. Arabidopsis CBF1 overexpression induces COR genes and enhances freezing tolerance. Science 280:104-106

James, V.A., I. Neibaur, and F. Altpeter. 2008. Stress inducible expression of the DREB1A transcription factor from xeric, Hordeum spontaneum L. in turf and forage grass (Paspalum notatum Flugge) enhances abiotic stress tolerance. Transgenic Res. 17:93-104.

Kant, P., M. Gordon, S. Kant, G. Zolla, O. Davydov, Y.M. Heimer, V. Chalifa-Caspi, R. Shaked, and S. Barak. 2008. Functional-genomics-based identification of genes that regulate Arabidopsis responses to multiple abiotic stresses. Plant Cell Environ. 31:697-714.

Karsten, U., K.D. Barrow, O. Nixdorf, and R.J. King. 1996. The compatibility with enzyme activity of unusual organic osmolytes from mangrove red algae. Aust. J. Plant Physiol. 23:577-582.

Kathuria, H., J. Giri, K.N. Nataraja, N. Murata, M. Udayakumar, and A.K. Tyagi. 2009. Glycinebetaine-induced water-stress tolerance in codAexpressing transgenic indica rice is associated with up-regulation of several stress responsive genes. Plant Biotechnol. J. 7:512-526.

Keller, F. and P. Matile. 1989. Storage of sugars and mannitol in petioles of celery leaves. New Phytol. 113:291-299.

Kishor, P., Z. Hong, G.H. Miao, C. Hu, and D.P. Verma. 1995. Overexpression of $[\Delta]$-pyrroline5-carboxylate synthetase increases proline production and confers osmotolerance in transgenic plants. Plant Physiol. 108:1387-1394.

Klingler, J.P., G. Batelli, and J.K. Zhu. 2010. ABA receptors: The START of a new paradigm in phytohormone signalling. J. Expt. Bot. 61: 3199-3210.

Ko, J.H., S.H. Yang, and K.H. Han. 2006. Upregulation of an Arabidopsis RING-H2 gene, $X E R I C O$, confers drought tolerance through increased abscisic acid biosynthesis. Plant J. 47:343-355

Kotuby-Amacher, J, R. Koenig, and B. Kitchen. 2000. Salinity and plant tolerance. <https:// extension.usu.edu/files/publications/publication/ AG-SO-03.pdf>.

Kronzucker, H.J. and D.T. Britto. 2011. Sodium transport in plants: A critical review. New Phytol. 189:54-81.

Läuchli, A. and U. Lüttge (eds.). 2002. Salinity: Environment-plants-molecules. Kluwer Academic, Dordrecht, The Netherlands.

Leidi, E.O., V. Barragan, L. Rubio, A. El Hamdaoui, M.T. Ruiz, B. Cubero, J.A. Fernandez, R.A. Bressan, P.M. Hasegawa, F.J. Quintero, and J.M. Pardo. 2010. The AtNHX1 exchanger mediates potassium compartmentation in vacuoles of transgenic tomato. Plant J. 61:495-506.

Li, C.L., J.A. Lv, X. Zhao, X.H. Ai, X.L. Zhu, M.C. Wang, S.Y. Zhao, and G.M. Xia. 2010a. TaCHP: A wheat zinc finger protein gene down-regulated by abscisic acid and salinity stress plays a positive role in stress tolerance. Plant Physiol. 154:211-221.

Li, Z., C.M. Baldwin, Q. Hu, H. Liu, and H. Luo. 2010b. Heterologous expression of Arabidopsis $\mathrm{H}^{+-}$pyrophosphatase enhances salt tolerance in transgenic creeping bentgrass (Agrostis stolonifera L.). Plant Cell Environ. 33:272-289.

Liu, H., Q. Wang, M. Yu, Y. Zhang, Y. Wu, and H. Zhang. 2008. Transgenic salt-tolerant sugar beet (Beta vulgaris L.) constitutively expressing an Arabidopsis thaliana vacuolar $\mathrm{Na}+/ \mathrm{H}+$ antiporter gene, AtNHX3, accumulates more soluble sugar but less salt in storage roots. Plant Cell Environ. 31:1325-1334.

Liu, Q., M. Kasuga, Y. Sakuma, H. Abe, S. Miura, K. Yamaguchi-Shinozaki, and K. Shinozaki. 1998. Two transcription factors, DREB1 and DREB2, with an EREBP/AP2 DNA binding domain separate two cellular signal transduction pathways in drought- and low-temperatureresponsive gene expression, respectively, in Arabidopsis. Plant Cell 10:1391-1406.

Loescher, W.H. and J.D. Everard. 2000. Regulation of sugar alcohol biosynthesis, p. 275299. In: Leegood, R.C., T.D. Sharkey, and S. vonCaemmerer (eds.). Photosynthesis: Physiology and metabolism. Kluwer Academic Publishers, Dordrecht, The Netherlands.

Lu, S.Y., Y.X. Jing, S.H. Shen, H.Y. Zhao, L.Q. Ma, X.J. Zhou, Q. Ren, and Y.F. Li. 2005. Antiporter gene from Hordeum brevisubulatum (Trin.) link and its overexpression in transgenic tobaccos. J. Integr. Plant Biol. 47:343-349.

Maruyama, K., Y. Sakuma, M. Kasuga, Y. Ito, M. Seki, H. Goda, Y. Shimada, S. Yoshida, K. Shinozaki, and K. Yamaguchi-Shinozaki. 2004. Identification of cold-inducible downstream genes of the Arabidopsis DREB1A/CBF3 transcriptional factor using two microarray systems. Plant J. 38:982-993.

Maser, P., S. Thomine, J.I. Schroeder, J.M. Ward, K. Hirschi, H. Sze, I.N. Talke, A. Amtmann, F.J.M. Maathuis, D. Sanders, J.F. Harper, J. Tchieu, M. Gribskov, M.W. Persans, D.E. Salt, S.A. Kim, and M.L. Guerinot. 2001. Phylogenetic relationships within cation transporter families of Arabidopsis. Plant Physiol. 126:1646-1667.

Mason, M.G., D. Jha, D.E. Salt, M. Tester, K. Hill, J.J. Kieber, and G.E. Schaller. 2010. Type-B response regulators ARR1 and ARR12 regulate expression of AtHKT1;1 and accumulation of sodium in Arabidopsis shoots. Plant J. 64:753-763.

Mikolajczyk, M., O.S. Awotunde, G. Muszyska, D.F. Klessig, and G. Dobrowolska. 2000. Osmotic stress induces rapid activation of a salicylic acid-induced protein kinase and a homolog of protein kinase ASK1 in tobacco cells. Plant Cell 12:165-178.

Miller, G., K. Schlauch, R. Tam, D. Cortes, M.A. Torres, V. Shulaev, J.L. Dangl, and R. Mittler. 
2009. The plant NADPH oxidase RBOHD mediates rapid systemic signaling in response to diverse stimuli. Sci. Signal. 2:A26-A35.

Mittler, R. and E. Blumwald. 2010. Genetic engineering for modern agriculture: Challenges and perspectives. Annu. Rev. Plant Biol. 61:443-462.

Mochida, K., T. Yoshida, T. Sakurai, K. YamaguchiShinozaki, K. Shinozaki, and L.S.P. Tran. 2010. Genome-wide analysis of two-component systems and prediction of stress-responsive twocomponent system members in soybean. DNA Res. 17:303-324.

Moller, I.S., M. Gilliham, D. Jha, G.M. Mayo, S.J. Roy, J.C. Coates, J. Haseloff, and M. Tester. 2009. Shoot $\mathrm{Na}^{+}$exclusion and increased salinity tolerance engineered by cell type-specific alteration of $\mathrm{Na}^{+}$transport in Arabidopsis. Plant Cell 21:2163-2178.

Munns, R. 1993. Physiological processes limiting plant growth in saline soils-Some dogmas and hypotheses. Plant Cell Environ. 16:15-24.

Munns, R. 2002. Comparative physiology of salt and water stress. Plant Cell Environ. 25:239-250.

Munns, R. 2009. Strategies for crop improvement in saline soils, p. 99-110. In: Ashraf, M., M. Oxturk, and H.R. Athar (eds.). Salinity and water stress: Improving crop efficiency. Springer, New York, NY.

Munns, R. and M. Tester. 2008. Mechanisms of salinity tolerance. Annu. Rev. Plant Physiol. Plant Mol. Biol. 59:651-681.

Nanjo, T., M. Kobayashi, Y. Yoshiba, Y. Kakubari, K. Yamaguchi-Shinozaki, and K. Shinozaki. 1999. Antisense suppression of proline degradation improves tolerance to freezing and salinity in Arabidopsis thaliana. FEBS Lett. 461:205-210.

National Research Council. 1989. Irrigationinduced water quality problems. National Academy of Sciences Press, Washington, DC.

Nevo, E. and G.X. Chen. 2010. Drought and salt tolerances in wild relatives for wheat and barley improvement. Plant Cell Environ. 33:670-685.

Niu, G. and R.I. Cabrera. 2010. Growth and physiological responses of landscape plants to saline water irrigation: A review. HortScience 45:1605-1609.

Nomura, M., M. Ishitani, T. Takabe, A.K. Rai, and T. Takabe. 1995. Synechococcus sp. PCC7942 transformed with Escherichia coli bet genes produces glycine-betaine from choline and acquires resistance to salt stress. Plant Physiol. 107:703-708.

Oh, D.H., S.Y. Lee, R.A. Bressan, D.J. Yun, and H.J. Bohnert. 2010. Intracellular consequences of SOS1 deficiency during salt stress. J. Expt. Bot. 61:1205-1213.

Oh, S.J., Y.S. Kim, C.W. Kwon, H.K. Park, J.S. Jeong, and J.K. Kim. 2009. Overexpression of the transcription factor AP37 in rice improves grain yield under drought conditions. Plant Physiol. 150:1368-1379.

Ohta, M., Y. Hayashi, A. Nakashima, A. Hamada, A. Tanaka, T. Nakamura, and T. Hayakawa. 2002. Introduction of a $\mathrm{Na}^{+} / \mathrm{H}^{+}$antiporter gene from Atriplex gmelini confers salt tolerance to rice. FEBS Lett. 532:279-282.

Omielan, J.A., E. Epstein, and J. Dvorak. 1991. Salt tolerance and ionic relations of wheat as affected byindividual chromosomes of salttolerant Lophopyrum elongatum. Genome 34: 961-974.

Park, S.Y., P. Fung, N. Nishimura, D.R. Jensen, H. Fujii, Y. Zhao, S. Lumba, J. Santiago, A. Rodrigues, T.F. Chow, S.E. Alfred, D. Bonetta, R. Finkelstein, N.J. Provart, D. Desveaux, P.L. Rodriguez, P. McCourt, J.K. Zhu, J.I. Schroeder, B.F. Volkman, and S.R. Cutler.
2009. Abscisic acid inhibits type $2 \mathrm{C}$ protein phosphatases via the PYR/PYL family of START proteins. Science 324:1068-1071.

Pasapula, V., G.X. Shen, S. Kuppu, J. Paez-Valencia, M. Mendoza, P. Hou, J.A. Chen, X.Y. Qiu, L.F. Zhu, X.L. Zhang, D. Auld, E. Blumwald, H. Zhang, R. Gaxiola, and P. Payton. 2011. Expression of an Arabidopsis vacuolar $\mathrm{H}^{+}$pyrophosphatase gene $(A V P I)$ in cotton improves drought- and salt tolerance and increases fibre yield in the field conditions. Plant Biotechnol. J. 9:88-99.

Pino, M.T., J.S. Skinner, E.J. Park, Z. Jeknic, P.M. Hayes, M.F. Thornashow, and T.H.H. Chen. 2007. Use of a stress inducible promoter to drive ectopic AtCBF expression improves potato freezing tolerance while minimizing negative effects on tuber yield. Plant Biotechnol. J. 5:591-604.

Plett, D., G. Safwat, M. Gilliham, I.S. Moller, S. Roy, N. Shirley, A. Jacobs, A. Johnson, and M. Tester. 2010. Improved salinity tolerance of rice through cell type-specific expression of AtHKT1;1. PLoS ONE 5.

Qiu, Q.S., Y. Guo, M.A. Dietrich, K.S. Schumaker, and J.K. Zhu. 2002. Regulation of SOS1, a plasma membrane $\mathrm{Na}^{+} / \mathrm{H}^{+}$exchanger in Arabidopsis thaliana, by SOS2 and SOS3. Proc. Natl. Acad. Sci. USA 99:8436-8441.

Rains, D.W., and S.S. Goyal. 2003. Strategies for managing crop production in saline environments: an overview. J. Crop Production 7:1-10.

Ren, Z.H., Z.M. Zheng, V. Chinnusamy, J.H. Zhu, X.P. Cui, K. Iida, and J.K. Zhu. 2010. RAS1, a quantitative trait locus for salt tolerance and ABA sensitivity in Arabidopsis. Proc. Natl. Acad. Sci. USA 107:5669-5674.

Rengasamy, P. 2006. World salinization with emphasis on Australia. J. Expt. Bot. 57:1017-1023.

Rengasamy, P. 2010. Soil processes affecting crop production in salt-affected soils. Funct. Plant Biol. 37:613-620.

Rhodes, D. and A.D. Hanson. 1993. Quaternary ammonium and tertiary sulfonium compounds in higher plants. Annu. Rev. Plant Physiol. Plant Mol. Biol. 44:357-384.

Rhodes, D., A. Nadolska-Orczyk, and P.J. Rich 2002. Salinity, osmolytes, and compatible solutes, p. 181-204. In: Läuchli, A. and U. Lüttge (eds.). Salinity: Environment-plants-molecules. Kluwer Academic, Dordrecht, The Netherlands.

Riadh, K., M. Wided, K. Hans-Werner, and A. Chedly. 2010. Responses of halophytes to environmental stresses with special emphasis to salinity. Adv. Bot. Res. 53:117-145.

Rivero, R.M., J. Gimeno, A. Van Deynze, H. Walia, and E. Blumwald. 2010. Enhanced cytokinin synthesis in tobacco plants expressing P-Sark:Ipt prevents the degradation of photosynthetic protein complexes during drought. Plant Cell Physiol. 51:1929-1941.

Rivero, R.M., M. Kojima, A. Gepstein, H. Sakakibara, R. Mittler, S. Gepstein, and E. Blumwald. 2007. Delayed leaf senescence induces extreme drought tolerance in a flowering plant. Proc. Natl. Acad. Sci. USA 104:19631-19636.

Robins, J.G., B.S. Bushman, and B.L. Waldron. 2009. Variation within Poa germplasm for salinity tolerance. HortScience 44:1517-1521.

Rozema, J. and T. Flowers. 2008. Crops for a salinized world. Science 322:1478-1480.

Saavedra, X., A. Modrego, D. Rodriguez, M.P. Gonzalez-Garcia, L. Sanz, G. Nicolas, and O. Lorenzo. 2010. The nuclear interactor PYL8/ RCAR3 of Fagus sylvatica FsPP2C1 is a positive regulator of abscisic acid signaling in seeds and stress. Plant Physiol. 152:133-150.

Santiago, J., A. Rodrigues, A. Saez, S. Rubio, R. Antoni, F. Dupeux, S.Y. Park, J.A. Marquez,
S.R. Cutler, and P.L. Rodriguez. 2009. Modulation of drought resistance by the abscisic acid receptor PYL5 through inhibition of clade A PP2Cs. Plant J. 60:575-588.

Schachtman, D.P., A.J. Bloom, and J. Dvorak. 1989. Salt-tolerant Triticum $\times$ Lophopyrum derivatives limit the accumulation of sodium and chloride ions under saline-stress. Plant Cell Environ. 12:47-55.

Seki, M., M. Narusaka, H. Abe, M. Kasuga, K. Yamaguchi-Shinozaki, P. Carninci, Y. Hayashizaki, and K. Shinozaki. 2001. Monitoring the expression pattern of 1300 Arabidopsis genes under drought and cold stresses by using a full-length cDNA microarray. Plant Cell 13: 61-72.

Seo, P.J., M.J. Kim, J.S. Song, Y.S. Kim, H.J. Kim, and C.M. Park. 2010. Proteolytic processing of an Arabidopsis membrane-bound NAC transcription factor is triggered by cold-induced changes in membrane fluidity. Biochem. J. 427:359-367.

Shen, B., R.G. Jensen, and H.J. Bohnert. 1997. Increased resistance to oxidative stress in transgenic plants by targeting mannitol biosynthesis to chloroplasts. Plant Physiol. 113:1177-1183.

Sheveleva, E., W. Chmara, H.J. Bohnert, and R.G. Jensen. 1997. Increased salt and drought tolerance by D-ononitol production in transgenic Nicotiana tabacum L. Plant Physiol. 115:1211-1219.

Shi, H.Z., M. Ishitani, C.S. Kim, and J.K. Zhu. 2000. The Arabidopsis thaliana salt tolerance gene SOS1 encodes a putative $\mathrm{Na}^{+} / \mathrm{H}^{+}$antiporter. Proc. Natl. Acad. Sci. USA 97:6896-6901.

Shi, H.Z., B.-H. Lee, S.-J. Wu, and J.K. Zhu. 2003. Overexpression of a plasma membrane $\mathrm{Na}^{+} / \mathrm{H}^{+}$ antiporter gene improves salt tolerance in Arabidopsis thaliana. Nature 21:81-85.

Shi, H.Z., F.J. Quintero, J.M. Pardo, and J.K. Zhu. 2002. The putative plasma membrane $\mathrm{Na}^{+} / \mathrm{H}^{+}$ antiporter SOS1 controls long-distance $\mathrm{Na}^{+}$ transport in plants. Plant Cell 14:465-477.

Shin, D., S.J. Moon, S. Han, B.G. Kim, S.R. Park, S.K. Lee, H.J. Yoon, H.E. Lee, H.B. Kwon, D. Baek, B.Y. Yi, and M.O. Byun. 2011. Expression of StMYB1R-1, a novel potato single MYB-like domain transcription factor, increases drought tolerance. Plant Physiol. 155:421-432.

Shinozaki, K., K. Yamaguchi-Shinozaki, and M. Seki. 2003. Regulatory network of gene expression in the drought and cold stress responses. Curr. Opin. Plant Biol. 6:410-417.

Sickler, C.M., G.E. Edwards, O. Kiirats, Z. Gao, and W. Loescher. 2007. Response of mannitolproducing Arabidopsis thaliana to abiotic stress. Func. Plant Biol. 34:382-391.

Sottosanto, J.B., A. Gelli, and E. Blumwald. 2004. DNA array analyses of Arabidopsis thaliana lacking a vacuolar $\mathrm{Na}^{+} / \mathrm{H}^{+}$antiporter: Impact of AtNHX1 on gene expression. Plant J. 40:752-771.

Storey, R. and R.R. Walker. 1998. Citrus and salinity. Sci. Hort. 78:39-81.

Szabolcs, I. 1989. Salt-affected soils. CRC, Boca Raton, FL.

Tarczynski, M.C., R.G. Jensen, and H.J. Bohnert. 1993. Stress protection of transgenic tobacco by production of the osmolyte mannitol. Science 259:508-510.

Tester, M. and P. Langridge. 2010. Breeding technologies to increase crop production in a changing world. Science 327:818-822.

Timasheff, S.N. 1993. The control of protein stability and association by weak interactions with water: How do solvents affect these processes. Annu. Rev. Biophys. Biomol. Struct. 22:67-97.

Tran, L.S.P., T. Urao, F. Qin, K. Maruyama, T. Kakimoto, K. Shinozaki, and K. YamaguchiShinozaki. 2007. Functional analysis of AHK1/ ATHK1 and cytokinin receptor histidine 
kinases in response to abscisic acid, drought, and salt stress in Arabidopsis. Proc. Natl. Acad. Sci. USA 104:20623-20628.

Urao, T., B. Yakubov, R. Satoh, K. YamaguchiShinozaki, M. Seki, T. Hirayama, and K. Shinozaki. 1999. A transmembrane hybridtype histidine kinase in Arabidopsis functions as an osmosensor. Plant Cell 11:1743-1754.

Vernon, D.M. and H.J. Bohnert. 1992. A novel methyl transferase induced by osmotic stress in the facultative halophyte Mesembryanthemum crystallinum. EMBO J. 11:2077-2085.

Vogel, J.T., D.G. Zarka, H.A. Van Buskirk, S.G. Fowler, and M.F. Thomashow. 2005. Roles of the CBF2 and ZAT12 transcription factors in configuring the low temperature transcriptome of Arabidopsis. Plant J. 41:195-211.

Ward, J.M., K.D. Hirschi, and H. Sze. 2003. Plants pass the salt. Trends Plant Sci. 8:200-201.

Winicov, I. 2000. Alfinl transcription factor overexpression enhances plant root growth under normal and saline conditions and improves salt tolerance in alfalfa. Planta 210: 416-422.

Witcombe, J.R., P.A. Hollington, C.J. Howarth, S. Reader, and K.A. Steele. 2008. Breeding for abiotic stresses for sustainable agriculture. Philosophical Transactions of the Royal Society BBiological Sciences 363:703-716.

Wu, S.J., L. Ding, and J.K. Zhu. 1996. SOS1, a genetic locus essential for salt tolerance and potassium acquisition. Plant Cell 8:617-627.

Xue, Z.Y., D.Y. Zhi, G.P. Xue, H. Zhang, Y.X. Zhao, and G.M. Xia. 2004. Enhanced salt tolerance of transgenic wheat (Triticum aestivum L.) expressing a vacuolar $\mathrm{Na}^{+} / \mathrm{H}^{+}$antiporter gene with improved grain yields in saline soils in the field and a reduced level of leaf $\mathrm{Na}^{+}$. Plant Sci. 167:849-859.

Yamada, M., H. Morishita, K. Urano, N. Shiozaki, K. Yamaguchi-Shinozaki, K. Shinozaki, and Y. Yoshiba. 2005. Effects of free proline accumulation in petunias under drought stress. J. Expt. Bot. 56:1975-1981

Yang, L.A., W. Ji, Y.M. Zhu, P. Gao, Y. Li, H. Cai, X. Bai, and D.J. Guo. 2010. GsCBRLK, a calcium/ calmodulin-binding receptor-like kinase, is a positive regulator of plant tolerance to salt and $\mathrm{ABA}$ stress. J. Expt. Bot. 61:2519-2533.

Yang, Q., Z.Z. Chen, X.F. Zhou, H.B. Yin, X. Li, X.F. Xin, X.H. Hong, J.K. Zhu, and Z.Z. Gong. 2009 Overexpression of $S O S$ (salt overly sensitive) genes increases salt tolerance in transgenic Arabidopsis. Molecular Plant 2:22-31.

Yang, W., X.D. Liu, X.J. Chi, C.A. Wu, Y.Z. Li, L.L. Song, X.M. Liu, Y.F. Wang, F.W. Wang, C.A. Zhang, Y. Liu, J.M. Zong, and H.Y. Li. 2011. Dwarf apple MbDREB1 enhances plant tolerance to low temperature, drought, and salt stress via both ABA-dependent and ABAindependent pathways. Planta 233:219-229.

Yin, X.Y., A.F. Yang, K.W. Zhang, and J.R. Zhang. 2004. Production and analysis of transgenic maize with improved salt tolerance by the introduction of AtNHX1 gene. Acta Bot. Sin. 7:12-20.

Zhang, H.X. and E. Blumwald. 2001. Transgenic salt-tolerant tomato plants accumulate salt in foliage but not in fruit. Nat. Biotechnol. 19:765-768.

Zhang, H.X., J.N. Hodson, J.P. Williams, and E. Blumwald. 2001. Engineering salt-tolerant Brassica plants: Characterization of yield and seed oil quality in transgenic plants with increased vacuolar sodium accumulation. Proc. Natl. Acad. Sci. USA 98:12832-12836.

Zhang, X., S.G. Fowler, H.M. Cheng, Y.G. Lou, S.Y. Rhee, E.J. Stockinger, and M.F. Thomashow. 2004. Freezing-sensitive tomato has a functional CBF cold response pathway, but a CBF regulon that differs from that of freezing-tolerant Arabidopsis. Plant J. 39:905-919.

Zhang, X., H.W. Ju, M.S. Chung, P. Huang, S.J. Ahn, and C.S. Kim. 2011. The R-R-type MYBLike transcription factor, AtMYBL, is involved in promoting leaf senescence and modulates an abiotic stress response in Arabidopsis. Plant Cell Physiol. 52:138-148.

Zhifang, G. and W. Loescher. 2003. Expression of a celery mannose 6-phosphate reductase in Arabidopsis thaliana enhances salt tolerance and induces biosynthesis of both mannitol and a glucosyl-mannitol dimer. Plant Cell Environ. 26:275-283.

Zhou, L., D.L. Creech, K.W. Krauss, Y. Yunlong, and D.L. Kulhavy. 2010. Can we improve the salinity tolerance of genotypes of Taxodium by using varietal and hybrid crosses? HortScience 45:1773-1778.

Zhu, J.K. 2002. Salt and drought stress signal transduction in plants. Annu. Rev. Plant Physiol. Plant Mol. Biol. 53:247-273. 